\title{
Comparison of the performance of direct fluorescent antibody staining, a point-of-care rapid antigen test and virus isolation with that of RT-PCR for the detection of novel 2009 influenza $A(H 1 N 1)$ virus in respiratory specimens
}

\author{
Tina Ganzenmueller, Jeanette Kluba, Birgit Hilfrich, Wolfram Puppe, \\ Willem Verhagen, Albert Heim, Thomas Schulz \\ and Cornelia Henke-Gendo \\ Institute of Virology, Hannover Medical School, Carl-Neuberg-Straße 1, 30625 Hannover, Germany
}

Correspondence

Tina Ganzenmueller

Ganzenmueller.Tina@

mh-hannover.de

Received 2 November 2009

Accepted 27 February 2010

\begin{abstract}
Although infections with the novel pandemic 2009 influenza A (H1N1) virus (A/H1N1/2009) appeared to be relatively mild during the first summer of circulation ('off season'), there has been significant morbidity and hospitalization and several fatal cases. Thus, rapid detection of $\mathrm{A} / \mathrm{H} 1 \mathrm{~N} 1 / 2009$ is crucial for efficient treatment and infection control measures. In contrast to seasonal influenza, where point-of-care (POC) rapid antigen tests and direct fluorescent antibody (DFA) staining ensure rapid detection, diagnosis of $\mathrm{A} / \mathrm{H} 1 \mathrm{~N} 1 / 2009$ has so far been based on RT-PCR. This study retrospectively compared the performance of the Quidel QuickVue POC test, DFA staining and virus isolation with that of RT-PCR for A/H1N1/2009 detection in 526 respiratory specimens collected during the first wave of the outbreak from May to September 2009. A/H1N1/2009 was detected in $9.1 \%(48 / 526)$ of samples. One hundred and thirty-seven of the A/H1N1/2009 PCR-negative samples were additionally tested using a RealAccurate Respiratory RT-PCR panel, revealing other respiratory viruses (mainly entero/ rhino- and adenoviruses) in 42.3\% (58/137). All methods analysed detected A/H1N1/2009 with excellent specificity but different sensitivities (POC test: 18.2\%; DFA staining: $38.7 \%$; virus isolation: $45.7 \%$ ). Therefore, the POC test was not suitable for diagnosis, detecting $\mathrm{A} / \mathrm{H} 1 \mathrm{~N} 1 / 2009$ only if present in high concentrations (corresponding median $C_{\mathrm{t}}$ value $=19.0$; range $=16.5-21.4)$. DFA staining was also able to detect $A / H 1 N 1 / 2009$ in specimens with a lower virus concentration (median $C_{t}$ value $=24.0$; range $=16.5-29.8$ ). Virus isolation, which was positive after a median time of 7.5 days, was too time-consuming. In summary, DFA staining is superior to POC testing and may be appropriate for patients expected to have a rather high level of virus replication. Nevertheless, in DFA-negative specimens, A/H1N1/2009 should be excluded by RT-PCR.
\end{abstract}

\section{INTRODUCTION}

The novel 2009 influenza A (H1N1) virus (A/H1N1/2009), which emerged in April 2009 in Mexico, rapidly spread worldwide leading to the declaration of a pandemic by the World Health Organization shortly after (Fraser et al., 2009; Zarocostas, 2009). Although human disease caused by $\mathrm{A} / \mathrm{H} 1 \mathrm{~N} 1 / 2009$ has so far appeared mostly to be relatively mild in Germany, a significant level of morbidity and hospitalization and several cases of severe illness

Abbreviations: $C_{t}$, threshold cycle; DFA, direct fluorescent antibody; MDCK, Madin-Darby canine kidney; NPV, negative predictive value; POC, point of care; PPV, positive predictive value. and death have been observed (Chowell et al., 2009; Jamieson et al., 2009; Perez-Padilla et al., 2009; Vaillant et al., 2009).

Rapid diagnosis of influenza is necessary to initiate antiviral therapy and infection control measures to reduce the spread of infection in healthcare settings, and leads to clinical and financial benefits (Barenfanger et al., 2000; Low, 2008). For rapid diagnosis of seasonal influenza A/B, several rapid antigen tests, also referred to as point-of-care (POC) tests, are available. POC immunoassays detect viral antigen and can generate a result within 15 min or less (Storch, 2003). In contrast to traditional laboratory assays, such as virus isolation from cell cultures or real- 
time PCR, POC tests are widely used in a routine clinical setting (D'Heilly et al., 2008; Noyola \& Demmler, 2000). Another rapid detection method for seasonal influenza is direct fluorescent antibody (DFA) staining of respiratory epithelial cells, which can generate results within 1-2 h (Habib-Bein et al., 2003; Smit et al., 2007) but requires specialized and experienced staff.

In contrast to seasonal influenza, the diagnosis of novel A/H1N1/2009 is currently based on RT-PCR only, a sensitive but time-consuming and costly method, which is not suitable for providing rapid diagnosis. To improve the clinical management of patients suspected to have A/H1N1/2009 infection, suitable rapid detection methods (POC tests or DFA staining) for A/H1N1/2009 would be useful. Several studies have investigated the diagnostic performance of these methods in different populations, with highly differing results and recommendations (Drexler et al., 2009; Faix et al., 2009; Ginocchio et al., 2009; Pollock et al., 2009; Vasoo et al., 2009). Thus, we evaluated the diagnostic use of the commercially available QuickVue Influenza A+B POC test (Quidel), DFA staining and virus isolation from Madin-Darby canine kidney (MDCK) cells for $\mathrm{A} / \mathrm{H} 1 \mathrm{~N} 1 / 2009$ detection in comparison with $\mathrm{A} / \mathrm{H} 1 \mathrm{N1} / 2009 \mathrm{RT}-\mathrm{PCR}$ in respiratory specimens which were collected during the first wave of A/H1N1/2009 infections between May and September 2009 in Germany. In addition, 137 of the A/H1N1/2009 PCRnegative samples were tested using an RT-PCR panel for other respiratory viruses.

\section{METHODS}

Specimens. Routine respiratory diagnostic samples, which were sent to our laboratory between May 2009 and September 2009 to rule out novel A/H1N1/2009, from 526 individuals [comprising outpatients $(n=402)$ and healthcare workers $(n=71)$ with mostly mild symptoms, and also inpatients $(n=53)]$ were analysed. Case definitions for novel influenza were used according to the recommendations of the National Reference Centre (Robert Koch Institute, Germany). Specimen types included nasopharyngeal swabs consisting of cotton swabs transported in 1-2 $\mathrm{ml}$ sterile saline, pharyngeal washes for which approximately $5-10 \mathrm{ml}$ sterile saline was used, and bronchoalveolar lavage samples.

'Respiratory pools' were built by pooling $0.5-1.0 \mathrm{ml}$ from each specimen into a fresh vial under sterile conditions if two or more specimens were available from the same patient (e.g. two swabs and one pharyngeal wash). This was carried out after excluding loss of sensitivity from the pool versus single sample testing (data not shown) in order to achieve an optimal detection rate and to reduce cost and hands-on time. A total of 526 samples (480 respiratory pools, 37 pharyngeal washes, seven nasopharyngeal swabs and two bronchoalveolar lavage samples) were analysed.

Statistical analysis. Statistical analysis was performed using SPSS version 16.0. $P$ values of $<0.05$ were considered significant. Pearson's $\chi^{2}$ test and a Mann-Whitney $U$ test were applied to determine the statistical significance of differences between groups. For comparison of the analytical properties of the POC test, DFA staining and virus isolation, specimens positive for $\mathrm{A} / \mathrm{H} 1 \mathrm{~N} 1 / 2009$ in the RT-PCR were considered to be true-positives. Sensitivity, specificity and positive (PPV) and negative (NPV) predictive values were calculated using standard formulae.

RNA extraction. Total viral RNA was extracted from a $140 \mu \mathrm{l}$ aliquot of the respiratory specimen using a QIAamp Viral RNA kit in a QIAcube (Qiagen) according to the manufacturer's instructions, eluted in a volume of $50 \mu \mathrm{l}$ and stored at $-80{ }^{\circ} \mathrm{C}$ if not tested immediately.

A/H1N1/2009 real-time RT-PCR. An A/H1N1/2009 PCR was performed for all 526 specimens using a one-step real-time RTPCR (RNA UltraSense One-Step Quantitative RT-PCR systems; Invitrogen) on $10 \mu$ l eluted RNA in an ABI 7500 Real-time PCR System under the following conditions: reverse transcription for $20 \mathrm{~min}$ at $50{ }^{\circ} \mathrm{C}$ and initial denaturation at $95{ }^{\circ} \mathrm{C}$ for $2 \mathrm{~min}$, followed by 45 cycles of $95{ }^{\circ} \mathrm{C}$ for $30 \mathrm{~s}$ and annealing and extension at $60{ }^{\circ} \mathrm{C}$ for $1 \mathrm{~min}$. Primers and probe sequences, as published by Panning et al. (2009), were purchased from TIB MolBiol. A single batch of positive controls was used, resulting in comparable cycle threshold $\left(C_{\mathrm{t}}\right)$ values between 29 and 31. This suggested that the viral RNA concentration in the specimens could be semi-quantified by correlation with the $C_{\mathrm{t}}$ values of the A/H1N1/2009 RT-PCR. Lower $C_{\mathrm{t}}$ values indicated a higher virus concentration.

To ensure efficient nucleic acid extraction, as well as to exclude PCR inhibition, specimens were spiked with mengovirus, and for each sample an additional mengovirus RT-PCR was performed as published previously (Costafreda et al., 2006).

RT-PCR for detection of respiratory viruses other than A/H1N1/2009. A commercially available real-time RT-PCR kit (RealAccurate Respiratory RT-PCR kit; Pathofinder) was used as described previously (Gottlieb et al., 2009) to detect the following respiratory viruses: adenovirus, coronavirus types OC43 and 229E, influenza virus types A and B, human metapneumovirus (HMPV), parainfluenza virus (PIV) types 1-4, respiratory syncytial virus (RSV) types $\mathrm{A}$ and $\mathrm{B}$, and rhino-/enterovirus.

POC test. The QuickVue Influenza A+B POC test (Quidel), a lateral-flow immunoassay, was performed for $172 / 526$ patients according to the manufacturer's instructions. Briefly, the dropper provided was used to transfer the recommended amount of liquid specimen into the extraction tube. In the case of swabs, the extraction reagent provided was added. Finally, the test strip was placed in the tube and the result was read after $10 \mathrm{~min}$.

DFA staining. For DFA staining, specimens were centrifuged for $10 \mathrm{~min}$ at $500 \mathrm{~g}$ and the cell pellet was resuspended in a small amount of PBS. Ten microlitres of the resuspended pellet was transferred to a slide well, air dried and fixed in acetone at $-20{ }^{\circ} \mathrm{C}$ for $10 \mathrm{~min}$, followed by staining with mouse FITC-labelled influenza A virus monoclonal antibody (LIGHT DIAGNOSTICS; Millipore). A positive result was indicated by the presence of at least one cell showing specific fluorescence using a fluorescence microscope (Zeiss Axioskop 40). Specimens with an inadequate number of respiratory cells were considered invalid for DFA. Results for DFA staining were available for $172 / 526$ patients.

Virus isolation. Virus isolation was performed for all 526 patients by application of 1-2 $\mathrm{ml}$ specimen onto MDCK cells, which were monitored at least twice weekly for up to 14 days for the emergence of a cytopathic effect. 


\section{RESULTS AND DISCUSSION}

\section{Patient demographics}

Respiratory specimens from 526 patients were investigated. The median age of the patients was 24 years (range 0-84) and $47.5 \%(250 / 526)$ were male.

\section{Results of the A/H1N1/2009 real-time RT-PCR}

In total, $48 / 526$ patients (9.1\%) had a positive result in the A/H1N1/2009 RT-PCR, with a median $C_{\mathrm{t}}$ value of 28.6 (range 16.5-36.5). Patients with a positive PCR result had a significantly lower age than patients with a negative PCR result $[P=0.015$; median age 19 years (range $2-51$ ) vs 25 years (range $0-84)]$. The positive rate was higher in male $(10.8 \% ; n=27 / 250)$ compared with female $(7.6 \%$; $n=$ 21/276) patients. These data correlated well with the epidemiological situation in Germany during the study period (Gilsdorf \& Poggensee, 2009).

\section{Other respiratory viruses detected by the RealAccurate Respiratory RT-PCR}

Almost one-third of the A/H1N1/2009 RT-PCR-negative samples $(137 / 478 ; 28.7 \%)$ were tested additionally using the RealAccurate Respiratory RT-PCR. In total, $42.3 \%$ (58/137) of these specimens were positive, and 55 were positive for one of the following viruses: rhino-/enterovirus (28/137), adenovirus (11/137), PIV (7/137), coronavirus (4/137), HMPV (2/137), RSV (1/137) and influenza A/B virus $(2 / 137)$. In $3 / 137$ specimens, more than one virus could be detected. Only 2/137 specimens were positive for seasonal influenza $\mathrm{A} / \mathrm{B}$ virus (which was also confirmed by an in-house PCR for seasonal influenza virus), indicating that, as expected, the prevalence of seasonal influenza strains, as well as other 'seasonal' viruses such as HMPV and RSV, was very low during the study period from May to September 2009. The high rate of entero-/rhinovirus detection is typical for the summer months (Weigl et al., 2007). These data indicated that additional diagnostic testing for other respiratory viruses is required for negative A/H1N1/2009 tests during a pandemic.

\section{Comparison of sensitivity, specificity and PPV and NPV of the POC test, DFA staining and virus isolation with those of the A/H1N1/2009 RT-PCR}

The analytical properties of the different methods are shown in Table 1. Both rapid detection methods, the QuickVue Influenza $\mathrm{A}+\mathrm{B}$ POC test and DFA staining ( $n=172 / 526$, including 44 samples positive upon A/H1N1/ 2009 RT-PCR), were able to detect A/H1N1/2009 virus with an excellent specificity and PPV of $100 \%$, although the sensitivity was very low for the POC test $(18.2 \%)$ and only moderate for the DFA staining $(38.7 \%)$. The NPVs of both methods (77.1 and $82.2 \%$, respectively) were comparable.

In addition to the rapid detection methods, we analysed the diagnostic performance of influenza virus isolation from cell culture for all 526 samples, finding a sensitivity of $45.7 \%$, specificity of $99.8 \%$, and a PPV of $95.5 \%$ and NPV of $94.8 \%$. However, the median time required for virus isolation was 7.5 (range 3-10) days, indicating that virus isolation is only appropriate as a long-term method.

Our data suggested that the present version of the Quidel QuickVue POC test is not suitable for excluding A/H1N1/ 2009 infection due to its low sensitivity. Reduced POC test sensitivity due to inappropriate sample collection was unlikely, as the number of invalid DFA tests (e.g. due to an inadequate number of respiratory cells in the sample) was very low during the study. Similarly, low sensitivities have been reported for other POC tests (21.2\%) and DFA staining (47.2\%) (Ginocchio et al., 2009). Another German study found an even lower sensitivity (11.1\%) for the BinaxNOW POC test (Drexler et al., 2009). In contrast to this, other studies found slightly higher sensitivities of the Quidel POC test for A/H1N1/2009 detection, ranging from 40 to $61 \%$ (Vasoo et al., 2009) or 35 to $67 \%$ (Faix et al., 2009). One group even reported a sensitivity of $93 \%$ for DFA staining, recommending the use

Table 1. Comparison of DFA staining, POC test and virus isolation for the detection of influenza A (H1N1) 2009 virus using RT-PCR results as the gold standard

\begin{tabular}{|lcccc|}
\hline Test & Sensitivity (\%) & Specificity (\%) & PPV (\%) & NPV (\%) \\
\hline Quidel POC test $^{*}$ & 18.2 & 100 & 100 & 78.1 \\
DFA staining* $^{*}$ & 38.7 & 100 & 100 & 82.2 \\
Virus isolation $\dagger$ & 45.7 & $99.8 \ddagger$ & $95.5 \$$ & $94.8 \$$ \\
\hline
\end{tabular}

${ }^{\star}$ Results from 172 specimens, including 44 A/H1N1/2009 RT-PCR-positive samples. Three of the 172 DFA stainings were invalid and therefore excluded from the calculation.

$\dagger$ Results from 526 specimens, including 46 A/H1N1/2009 RT-PCR-positive samples. Twenty of the 526 cell cultures were not interpretable due to bacterial or fungal contamination.

¥Isolation of influenza virus $B$ in one patient with a negative A/H1N1/2009 RT-PCR result.

§Due to the differing sample sizes within the test groups, the NPV and PPV of virus isolation were not directly comparable to the NPVs and PPVs of the POC test and DFA. 
of DFA alone to rule out $\mathrm{A} / \mathrm{H} 1 \mathrm{N1} / 2009$ infection (Pollock et al., 2009). However, in this study, only DFA-positive samples and samples from inpatients were confirmed by A/H1N1/2009 RT-PCR, resulting in a very high sensitivity of DFA staining.

\section{Correlation of A/H1N1/2009 RT-PCR $C_{t}$ values with the results of the POC test, DFA staining and virus isolation}

Comparison of the semi-quantified A/H1N1/2009 concentration with the results of the POC test, DFA staining and virus isolation revealed that positivity was related to the amount of virus present in the specimens (Fig. 1). Samples that tested positive by the POC test, DFA staining or virus isolation had a significantly lower median $C_{\mathrm{t}}$ value than samples that tested negative by the respective methods $(P<0.001)$. Interestingly, a few samples showed negative results in either the POC test or DFA staining, despite high virus concentration. We speculate that the influenza A virus monoclonal antibodies used in the respective tests were not able to recognize the viral antigens in these specimens, possibly due to epitope mutations.

Consistent with our results, it has been reported that various POC tests (including Quidel QuickVue) detect $\mathrm{A} / \mathrm{H} 1 \mathrm{~N} 1 / 2009$ if high virus concentrations are present, as determined by serial dilutions of A/H1N1/2009 cell culture isolates (Hurt et al., 2009).

Notably, samples that tested positive by DFA staining (median $C_{\mathrm{t}}$ value $=24.0$, range 16.5-29.8) contained a concentration of $\mathrm{A} / \mathrm{H} 1 \mathrm{~N} 1 / 2009$ that was up to $\sim 9 C_{\mathrm{t}}$ values (corresponding to up to $3 \log$ steps) lower than that of samples with a positive POC test result (median $C_{\mathrm{t}}$ value $=19.0$, range 16.5-21.4). This indicated that DFA staining is more useful for an early diagnosis of $\mathrm{A} / \mathrm{H} 1 \mathrm{~N} 1 /$
2009 infection in cases with a moderate to high viral load in the respiratory tract.

Compared with previously published studies (Faix et al., 2009; Pollock et al., 2009; Vasoo et al., 2009), both the Quidel POC test and DFA staining had a low sensitivity in our study. This might be related to our study population, which consisted mainly of healthcare workers and outpatients with mostly mild symptoms, where A/H1N1/2009 infection had to be excluded due to infection control measures. Thus, lower virus replication might be assumed. Interestingly, the respiratory specimens of the only two A/H1N1/2009-positive inpatients showed high A/H1N1/ 2009 concentrations ( $C_{\mathrm{t}}$ values of 17.6 and 18.6). The POC test, as well as DFA staining, were positive in both patients. This finding suggests a potentially better performance of both rapid test methods in more severely affected, hospitalized individuals. Therefore, the application of strict clinical case definitions for influenza-like illness might improve the diagnostic yield of rapid test methods.

\section{Conclusions}

Although our data indicated that DFA staining is superior to POC testing for rapid detection of $\mathrm{A} / \mathrm{H} 1 \mathrm{~N} 1 / 2009$, both methods were clearly less sensitive than the A/H1N1/2009 RT-PCR. Consequently, the negative results from these rapid detection methods cannot exclude novel influenza A/H1N1/2009 confidently and thus results should be verified by further PCR testing. Additionally, the data concerning the prevalence of other respiratory viruses indicated that these viruses should also be kept in mind during a pandemic.

The development of new or adaptation of existing assays for the rapid and sensitive detection of the novel A/H1N1/ 2009 will be necessary in order to improve the diagnosis and treatment of $\mathrm{A} / \mathrm{H} 1 \mathrm{~N} 1 / 2009$-related influenza. Until these assays are established, DFA staining can be useful for

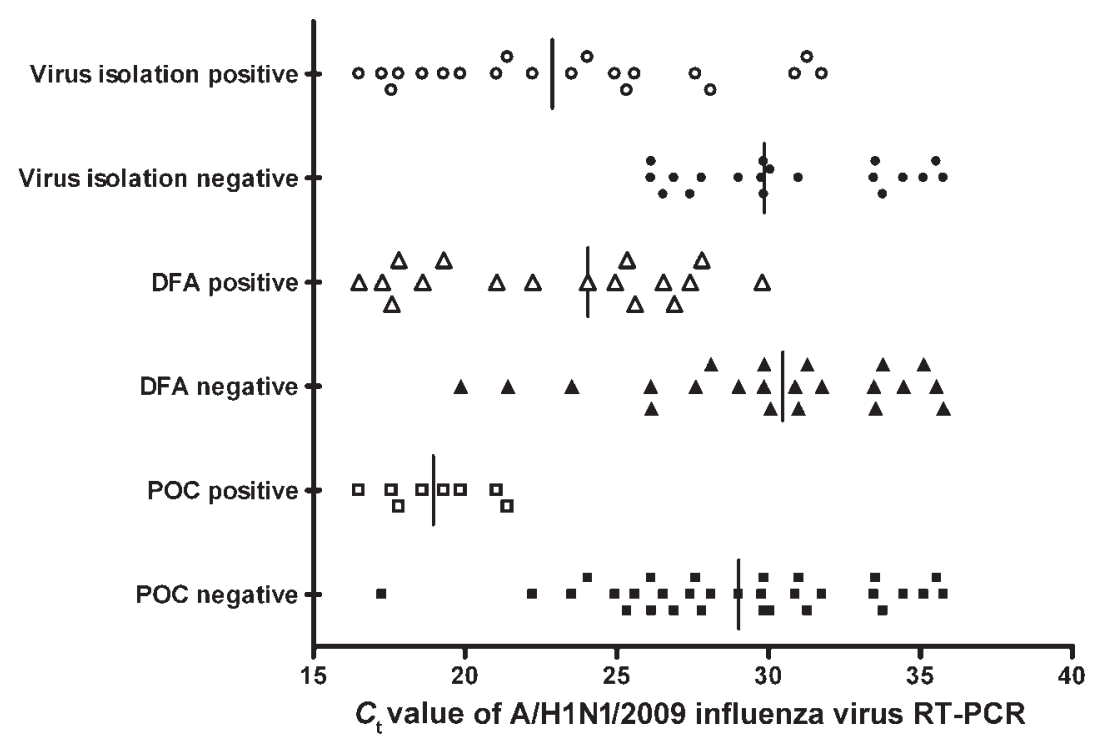

Fig. 1. Correlation of results of the POC test, DFA staining and virus isolation with $\mathrm{A} / \mathrm{H} 1 \mathrm{~N} 1 /$ 2009 RT-PCR $C_{t}$ values for semi-quantification. The results of the semi-quantification of the $\mathrm{A} / \mathrm{H} 1 \mathrm{~N} 1 / 2009$ concentration in 39 specimens tested with all three methods are shown. The A/H1N1/2009 concentration was significantly higher in specimens with a positive result than in specimens with a negative result from any individual method (e.g. POC test positive vs $\mathrm{POC}$ test negative) $(P<0.001)$. Vertical lines indicate the median $C_{\mathrm{t}}$ value. 
rapid diagnosis in patients expected to have a rather high level of A/H1N1/2009 replication. Nevertheless, in DFAnegative specimens, A/H1N1/2009 should be excluded by using RT-PCR as a standard diagnostic tool.

\section{ACKNOWLEDGEMENTS}

We thank the diagnostic staff of the units for PCR and virus isolation of the Institute of Virology for their excellent technical assistance.

\section{REFERENCES}

Barenfanger, J., Drake, C., Leon, N., Mueller, T. \& Troutt, T. (2000). Clinical and financial benefits of rapid detection of respiratory viruses: an outcomes study. J Clin Microbiol 38, 2824-2828.

Chowell, G., Bertozzi, S. M., Colchero, M. A., Lopez-Gatell, H., Alpuche-Aranda, C., Hernandez, M. \& Miller, M. A. (2009). Severe respiratory disease concurrent with the circulation of H1N1 influenza. $N$ Engl J Med 361, 674-679.

Costafreda, M. I., Bosch, A. \& Pinto, R. M. (2006). Development, evaluation, and standardization of a real-time TaqMan reverse transcription-PCR assay for quantification of hepatitis A virus in clinical and shellfish samples. Appl Environ Microbiol 72, 3846-3855.

D’Heilly, S. J., Janoff, E. N., Nichol, P. \& Nichol, K. L. (2008). Rapid diagnosis of influenza infection in older adults: influence on clinical care in a routine clinical setting. J Clin Virol 42, 124-128.

Drexler, J. F., Helmer, A., Kirberg, H., Reber, U., Panning, M., Muller, M., Hofling, K., Matz, B., Drosten, C. \& other authors (2009). Poor clinical sensitivity of rapid antigen test for influenza A pandemic (H1N1) 2009 virus. Emerg Infect Dis 15, 1662-1664.

Faix, D. J., Sherman, S. S. \& Waterman, S. H. (2009). Rapid-test sensitivity for novel swine-origin influenza A (H1N1) virus in humans. N Engl J Med 361, 728-729.

Fraser, C., Donnelly, C. A., Cauchemez, S., Hanage, W. P., Van Kerkhove, M. D., Hollingsworth, T. D., Griffin, J., Baggaley, R. F., Jenkins, H. E. \& other authors (2009). Pandemic potential of a strain of influenza A (H1N1): early findings. Science 324, 1557-1561.

Gilsdorf, A. \& Poggensee, G. (2009). Influenza A(H1N1)V in Germany: the first 10,000 cases. Euro Surveill 14, pii=19318.

Ginocchio, C. C., Zhang, F., Manji, R., Arora, S., Bornfreund, M., Falk, L., Lotlikar, M., Kowerska, M., Becker, G. \& other authors (2009). Evaluation of multiple test methods for the detection of the novel 2009 influenza A (H1N1) during the New York City outbreak. J Clin Virol 45, 191-195.

Gottlieb, J., Schulz, T. F., Welte, T., Fuehner, T., Dierich, M., Simon, A. R. \& Engelmann, I. (2009). Community-acquired respiratory viral infections in lung transplant recipients: a single season cohort study. Transplantation 87, 1530-1537.
Habib-Bein, N. F., Beckwith, W. H., III, Mayo, D. \& Landry, M. L. (2003). Comparison of SmartCycler real-time reverse transcriptionPCR assay in a public health laboratory with direct immunofluorescence and cell culture assays in a medical center for detection of influenza A virus. J Clin Microbiol 41, 3597-3601.

Hurt, A. C., Baas, C., Deng, Y. M., Roberts, S., Kelso, A. \& Barr, I. G. (2009). Performance of influenza rapid point-of-care tests in the detection of swine lineage $\mathrm{A}(\mathrm{H} 1 \mathrm{~N} 1)$ influenza viruses. Influenza Other Respi Viruses 3, 171-176.

Jamieson, D. J., Honein, M. A., Rasmussen, S. A., Williams, J. L., Swerdlow, D. L., Biggerstaff, M. S., Lindstrom, S., Louie, J. K., Christ, C. M. \& other authors (2009). H1N1 2009 influenza virus infection during pregnancy in the USA. Lancet 374, 451-458.

Low, D. (2008). Reducing antibiotic use in influenza: challenges and rewards. Clin Microbiol Infect 14, 298-306.

Noyola, D. E. \& Demmler, G. J. (2000). Effect of rapid diagnosis on management of influenza A infections. Pediatr Infect Dis J 19, 303307.

Panning, M., Eickmann, M., Landt, O., Monazahian, M., Olschlager, S., Baumgarte, S., Reischl, U., Wenzel, J. J., Niller, H. H. \& other authors (2009). Detection of influenza A(H1N1)v virus by real-time RT-PCR. Euro Surveill 14, pii $=19329$.

Perez-Padilla, R., de la Rosa-Zamboni, D., Ponce de Leon, S., Hernandez, M., Quinones-Falconi, F., Bautista, E., RamirezVenegas, A., Rojas-Serrano, J., Ormsby, C. E. \& other authors (2009). Pneumonia and respiratory failure from swine-origin influenza A (H1N1) in Mexico. N Engl J Med 361, 680-689.

Pollock, N. R., Duong, S., Cheng, A., Han, L. L., Smole, S. \& Kirby, J. E. (2009). Ruling out novel H1N1 influenza virus infection with direct fluorescent antigen testing. Clin Infect Dis 49, e66-e68.

Smit, M., Beynon, K. A., Murdoch, D. R. \& Jennings, L. C. (2007). Comparison of the NOW Influenza A \& B, NOW Flu A, NOW Flu B, and Directigen Flu $\mathrm{A}+\mathrm{B}$ assays, and immunofluorescence with viral culture for the detection of influenza A and B viruses. Diagn Microbiol Infect Dis 57, 67-70.

Storch, G. A. (2003). Rapid diagnostic tests for influenza. Curr Opin Pediatr 15, 77-84.

Vaillant, L., La Ruche, G., Tarantola, A. \& Barboza, P. (2009). Epidemiology of fatal cases associated with pandemic H1N1 influenza 2009. Euro Surveill 14, pii $=19309$.

Vasoo, S., Stevens, J. \& Singh, K. (2009). Rapid antigen tests for diagnosis of pandemic (swine) influenza A/H1N1. Clin Infect Dis 49, 1090-1093.

Weigl, J. A., Puppe, W., Meyer, C. U., Berner, R., Forster, J., Schmitt, H. J. \& Zepp, F. (2007). Ten years' experience with year-round active surveillance of up to 19 respiratory pathogens in children. Eur J Pediatr 166, 957-966.

Zarocostas, J. (2009). World Health Organization declares A (H1N1) influenza pandemic. BMJ 338, b2425. 